\title{
Interactive comment on "Evolution of Anthropogenic Air Pollutant Emissions in Guangdong Province, China, from 2006 to 2015" by Yahui Bian et al.
}

\section{anonymous}

ncl_talk@126.com

Received and published: 27 May 2019

This paper shows the long-term evolution (2006 2015) of anthropogenic emissions in Guangdong Province of China, to reveal the causes of source-contribution changes during this periods. The conclusions obtained in this paper are of great significance for the deep understanding of regional pollution emission characteristics, and have important guiding for co-control strategies on regional atmospheric pollution. The datasets produced by the article are conducive to the in-depth study of scientific issues in related fields. Thereforeiij Ňthis paper is strongly recommended for publication. 
2019.

ACPD

Interactive

comment

Printer-friendly version

Discussion paper 